\title{
Innocent murmurs and third heart sounds in Black schoolchildren ${ }^{\star}$
}

\author{
MARGARET J MCLAREN $†$, ANTHONY S LACHMAN†, WENDY A POCOCK, \\ JOHN B BARLOW
}

From the Cardiovascular Research Unit, Department of Medicine, University of the Witwatersrand; and the Cardiac Clinic, General Hospital, fohannesburg, South Africa

SUMMARY Normal auscultatory findings were studied during a heart survey in which 12050 Black schoolchildren, aged 2 to 18 years, were examined by cardiologists. Physiological third heart sounds were detected in 96 per cent of children, innocent systolic murmurs in 72 per cent, and innocent mid-diastolic murmurs in $\mathbf{0 . 2 7}$ per cent. The term 'innocent systolic murmur' was used for vibratory systolic murmurs $(70 \%)$ and pulmonary ejection systolic murmurs $(4.2 \%)$ but distinct separation of these two murmurs was often difficult. Vibratory systolic murmurs were present throughout the age range. Important features in differentiating innocent systolic murmurs from those caused by mild organic heart disease included the intonation, site of maximal intensity, timing in systole, and behaviour with postural change. Innocent mid-diastolic murmurs are short murmurs occurring immediately after the third heart sound in children, with no supportive evidence of organic heart disease.

Cardiology has made considerable progress over the past half century and improvement in diagnostic and surgical techniques has led to an increased understanding of many forms of heart disease and their management. Of equal importance is the definition of the auscultatory features of the healthy heart and the recognition of normal variations. In 1909, George Still ${ }^{1}$ gave his classical description of the vibratory systolic murmur and, nearly two decades later, Mackenzie ${ }^{2}$ still campaigned for the widespread medical acceptance of innocent systolic murmurs. It was not possible at that time to differentiate these from abnormal murmurs except by the exclusion of other evidence of organic heart disease. Levine ${ }^{3} 4$ introduced a classification of systolic murmurs based on intensity alone. This classification is excellent for record purposes but is of limited value in predicting the innocent or pathological nature of a systolic murmur. $^{5}$ Leatham ${ }^{6}$ classified systolic murmurs into ejection and regurgitant types on the basis of anatomical and haemodynamic considerations and he later clarified ${ }^{7}$ some of the auscultatory features

\footnotetext{
*Supported by the South African Medical Research Council, AngloAmerican Corporation of South Africa Ltd, South African Breweries Institute, and the Stella and Paul Loewenstein Cardiac Fund of the University of the Witwatersrand.

tPresent address: Cardiology Unit, New Britain General Hospital, New Britain, Connecticut, USA.

Received for publication 23 July 1979
}

of the normal heart. There have been subsequent contributions, ${ }^{8-10}$ and today the clinical recognition of an innocent murmur usually presents little difficulty to the skilled auscultator. ${ }^{11}$ This recognition is of the utmost importance ${ }^{12-14}$ since innocent praecordial murmurs occur most frequently in children and young adults and are commonly detected when auscultation is performed as part of routine examinations at schools or during unrelated illnesses. In such instances, young patients and their parents need positive reassurance that there is no organic cardiac lesion in order to avoid incorrect management or even the development of a cardiac neurosis..$^{15-17}$

Several studies on the incidence of innocent systolic murmurs have been reported. ${ }^{812} 18$ In one series, ${ }^{18} 96$ per cent of healthy children between 3 and 14 years of age had a systolic murmur. In Johannesburg, a survey on 200 White schoolchildren, ${ }^{12}$ aged 2 to 12 years, yielded a prevalence rate for innocent murmurs of 84 per cent. In May 1972 , a survey ${ }^{19}$ was undertaken on Black schoolchildren of the South Western Townships near Johannesburg (Soweto) with the primary objective of determining the incidence of rheumatic heart disease. The large number of children who had to be examined provided the opportunity of making other cardiological observations, including the incidence of non-ejection systolic clicks and as- 
sociated mitral systolic murmurs ${ }^{20}$ as well as congenital heart disease. ${ }^{21} \mathrm{We}$ now present and discuss data on the incidence of innocent murmurs and physiological third heart sounds.

\section{Subjects and methods}

A stratified random sample of 12050 children from crèches and schools of Soweto were examined during the period of May to October 1972. A detailed account of the sampling technique and methods has been given previously ${ }^{19}$ but relevant features will be repeated. The ages of the children ranged from 2 to 18 years (Fig. 1), and the number of boys and girls was equal. when it was heard in the absence of any abnormal cardiac findings ${ }^{714}$. Thus third heart sounds associated with non-ejection clicks or late systolic murmurs were excluded from the analysis.

\section{Innocent systolic murmurs}

The two innocent systolic murmurs assessed were the vibratory systolic murmur ${ }^{1}$ and the pulmonary ejection systolic murmur. Though some authors ${ }^{15} 16$ have suggested that the term 'innocent systolic murmur' be used for all unimportant murmurs, we excluded murmurs resulting from haemodynamically insignificant congenital anomalies such as minute ventricular septal defects ${ }^{22}$. Such murmurs are not completely innocuous since the lesions which give
Fig. 1 Age distribution of schoolchildren in the Soweto heart survey. The age was not stated (NS) on the forms of about 1 per cent.

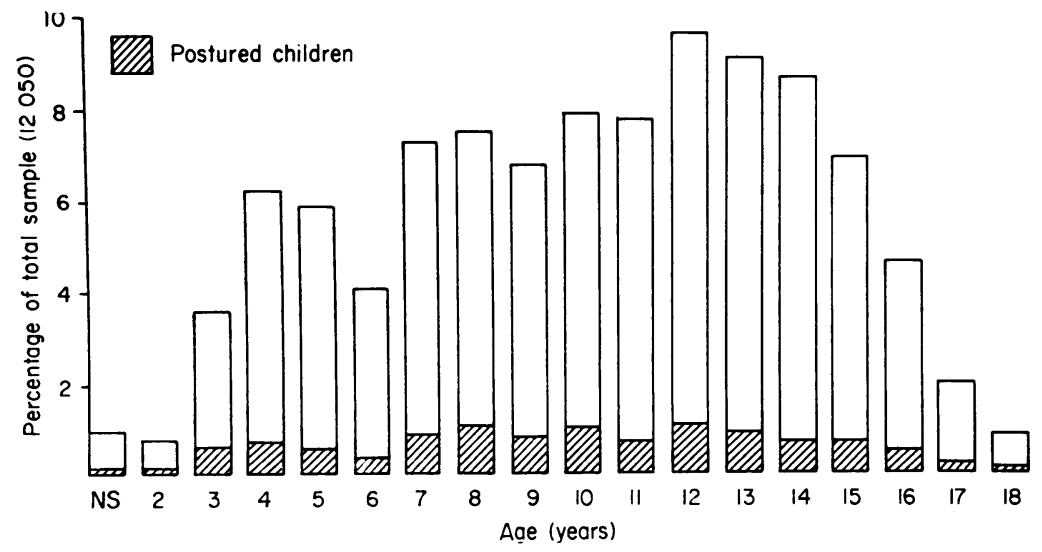

\section{EXAMINATION}

The medical team consisted of five cardiologists and five physicians who had all received at least six months' training in this cardiac unit. Three observers, at least one of whom was a senior cardiologist, were present at each session. Auscultation was performed on all children in the supine and left lateral positions. A random 10 per cent (Fig. 1) of the sample was also examined in the erect and squatting postures. Children with normal hearts were examined by one observer only, but if an abnormal murmur was suspected or detected, the children were examined independently by all three observers. ${ }^{19}$ The finding of an 'innocent' mid-diastolic murmur had to be confirmed by at least one other observer and an electrocardiogram was also recorded. Examinations were carried out on three days a week over a five-month period. The average rate of auscultation of children with normal hearts was 25 an hour for each observer.

DIAGNOSTIC CRITERIA

Physiological third heart sounds

A third heart sound was regarded as physiological rise to them may still act as a potential nidus for infective endocarditis. ${ }^{10}$

The diagnostic criteria for vibratory and pulmonary ejection murmurs were those previously described. ${ }^{7} 923$ A vibratory systolic murmur is a short crescendo-decrescendo murmur with a characteristic low-frequency musical or buzzing intonation. It is commonly of maximal intensity just inside the apex or at the left sternal border, but is frequently audible over the entire praecordium. It has a characteristic behaviour with posture, becoming softer or disappearing on standing and reappearing on squatting. ${ }^{13}{ }^{24}$ The innocent pulmonary ejection systolic murmur is high-pitched and has a blowing quality. It is usually loudest at the second left interspace, but may also be heard over the aortic area, left sternal border, apex, and the neck, especially on the left side. ${ }^{12} 1325$ The second heart sound must be normally split and the components of normal intensity. ${ }^{726}$

\section{'Innocent' mid-diastolic murmurs}

We have applied this term to the vibrations which are heard as a short murmur immediately following 
a third heart sound in some apparently normal young subjects (Fig. 2) with no supportive evidence of organic heart disease. ${ }^{14} 2728$

\section{ANALYSIS}

The variation in prevalence of these auscultatory findings with age, sex, and individual observer experience was assessed. A $x^{2}$ test for homogeneity was used to assess differences. However, the large
$(\mathrm{P}<0.0001)$, the range of 93 to 98 per cent is not clinically meaningful (Fig. 3). Excluding one observer (observer D, Fig. 4), who recorded a prevalence rate of 89 per cent, there was minimal variation in the prevalence rates among the observers.

Of the third heart sounds, 26 per cent occurred as an isolated finding and 74 per cent were associated with an innocent murmur. In the routinely postured group, $1107(94.3 \%)$ of the 1174 children

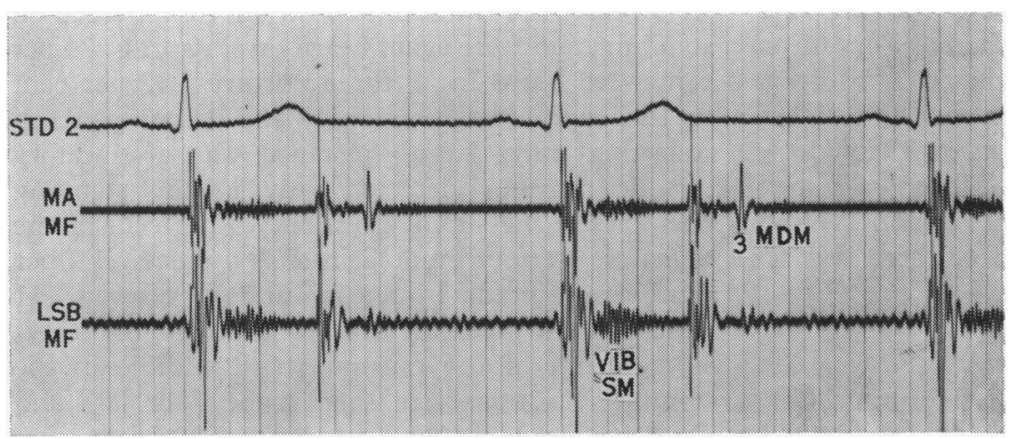

Fig. 2 Phonocardiogram recorded on medium frequency (MF) at the mitral area (MA) and left sternal border (LSB) in an apparently normal 9-year-old child. Regular, low frequency vibrations of a vibratory systolic murmur (VIB.SM), a third heart sound (3), and a soft short mid-diastolic murmur (MDM) are shown.

sample size necessary for the estimation of the prevalence of rheumatic heart disease rendered significance tests of little value in the analysis of common findings such as third heart sounds and vibratory systolic murmurs. In many instances, small variations in prevalence of no clinical importance were shown to be highly significant $(P<0.0001)$. The behaviour of third heart sounds and vibratory systolic murmurs with postural change was noted.

\section{Results}

Of the total of 12050 children, $11754(97 \cdot 5 \%)$ had normal hearts. Rheumatic heart disease ${ }^{19}$ was diagnosed in 80 children (6.9 per 1000), mitral valve prolapse $\mathrm{e}^{20}$ in 168 (13.4 per 1000), and congenital heart disease $\mathrm{e}^{21}$ in 48 (3.9 per 1000). The overall prevalence of the auscultatory features in children with normal hearts was 96 per cent for third heart sounds, 72 per cent for innocent systolic murmurs, and 0.27 per cent for innocent middiastolic murmurs. In only 246 children $(2 \cdot 1 \%)$ was neither a third heart sound nor an innocent murmur detected.

\section{PHYSIOLOGICAL THIRD HEART SOUNDS}

A physiological third heart sound was present in 11289 children $(96.0 \%)$ and occurred with equal frequency in both sexes. Though significant variation in prevalence with age was shown had third heart sounds. All of these were present in the supine position. In 86 per cent, the third heart sound disappeared on standing but was again heard on squatting, in 9 per cent it remained in all three postures, and in 5 per cent it was present in the supine position only.

\section{INNOCENT SYSTOLIC MURMURS}

An innocent systolic murmur was present in 8475 children $(72 \cdot 1 \%)$ with normal hearts.

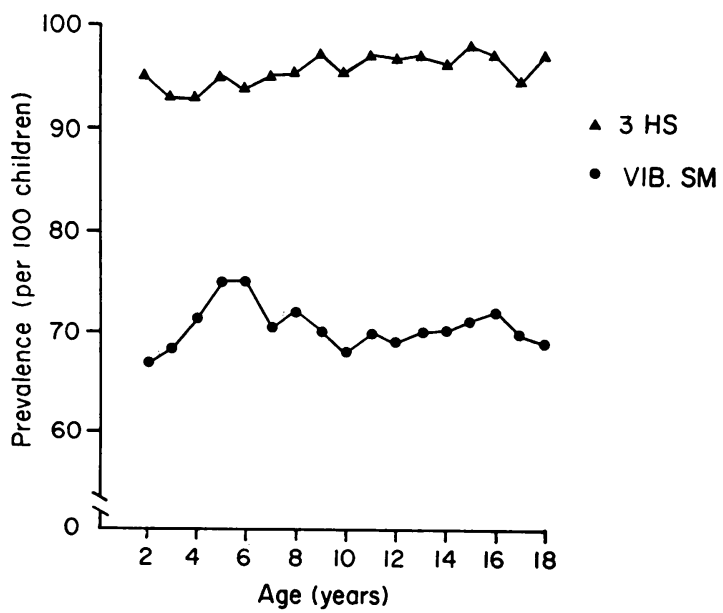

Fig. 3 Variation in prevalence of third heart sounds (3HS) and vibratory systolic murmurs (VIB.SM) with age. 
Vibratory systolic murmurs

Vibratory systolic murmurs were detected in 70.3 per cent (8264) of children with normal hearts and were of equal prevalence in both sexes. Though the relation between prevalence and age was again statistically significant $(P<0.0001)$, in clinical terms this was not impressive apart from a small peak in 5- to 6-year-old children (Fig. 3). There was a clinically significant variation in the prevalence among the individual auscultators (Fig. 4), and this could not be explained by differences in the ages of the children examined by them. The mean prevalence for the more experienced observers (A, B, D, F, G, and I) was 74 per cent and within this group there was minimal variation ( 73 to $75 \%$ ), whereas the mean prevalence in children examined by the less-skilled auscultators (C, E, and $\mathrm{H}$ ) and observer $\mathrm{J}$ who examined only 65 children was 66 per cent.

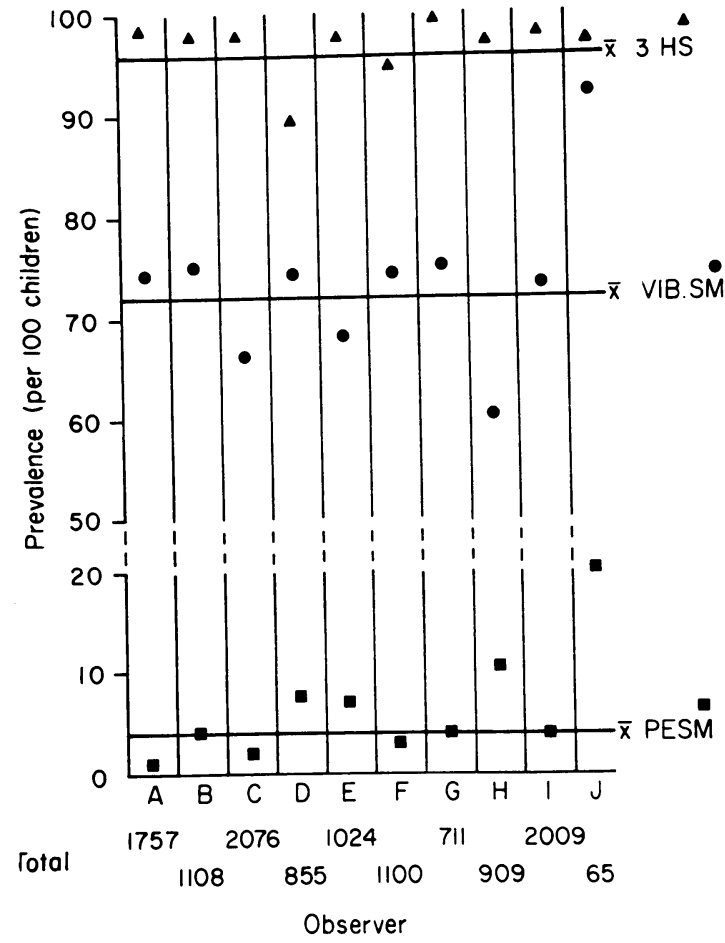

Fig. 4 Individual observer $(A-\mathcal{F})$ prevalence rates of physiological third heart sounds (3HS), vibratory systolic murmurs (VIB.SM), and pulmonary ejection systolic murmurs (PESM) in Soweto schoolchildren.

In 99 per cent of children with vibratory systolic murmurs, a physiological third heart sound was also present. The most frequent site of maximal intensity of the murmur was the left sternal border
$(62 \%)$, followed by both the left sternal border and apex $(17 \%)$, and the apex alone $(11 \%)$. The murmur was loudest at the second left interspace in 1 per cent only and in the remainder $(9 \%)$ at various combinations of these three sites.

Of the routinely postured children, $768(65.4 \%)$ had vibratory systolic murmurs. The prevalence of these murmurs in the supine, standing, and squatting positions was $64.7,15.9$, and 57 per cent, respectively. Sixty-three per cent of the murmurs were present in the supine position, disappeared on standing, and were again heard on squatting; 24 per cent were heard in all three postures; 12 per cent in the supine position only, and 1 per cent on squatting only. In no instance was a vibratory systolic murmur detected only in the standing position. In the supine position, 95 per cent of the murmurs were of grade 2 intensity or less, 4.9 per cent were of grade 3 intensity, and 0.1 per cent ( 11 children) the murmur was of grade 4 intensity; 99 per cent of the murmurs still audible in the standing position were then grade 2 or less and none was grade 4 . On squatting, 96 per cent were grade 2 or less and the remainder were grade 3.

\section{Pulmonary ejection systolic murmurs}

Innocent pulmonary ejection systolic murmurs were recorded in 492 of the children with normal hearts $(4 \cdot 2 \%)$. They were more frequent in girls with a ratio of $1.5: 1$ and the 15- to 18-year age group had the highest prevalence (Fig. 5). There was a significant variation in the prevalence rates among the individual observers and this was still present when the less experienced observers were excluded from the analysis $(P<0.001)$. The mean prevalence of the more experienced group was 3.64 per cent, whereas the less experienced auscultators recorded a higher rate of $5 \cdot 28$ per cent.

\section{INNOCENT MID-DIASTOLIC MURMURS}

A short mid-diastolic murmur was heard in 32 $(0 \cdot 27 \%)$ of the children who had no other evidence of heart disease and were classified as 'normal'. Twenty-one of these children were boys. The prevalence was 0.32 per cent in 2- to 6-year-old children, 0.32 per cent in those aged 7 to 10 years, 0.16 per cent in 11 to 14 -year-olds, and 0.39 per cent in the 15- to 18-year age group. The youngest child with this murmur was 3 years of age. All but three of the murmurs were detected by the more experienced auscultators. With only one exception, a vibratory systolic murmur was always an associated feature. However, none of them had an associated pulmonary ejection systolic murmur. The diastolic murmur was best heard at the apex in 25 subjects, at the left sternal border in six, and at both these 
sites in one. The electrocardiograms were normal in all of the children with this murmur, there were no obvious chest deformities, and the children appeared well.

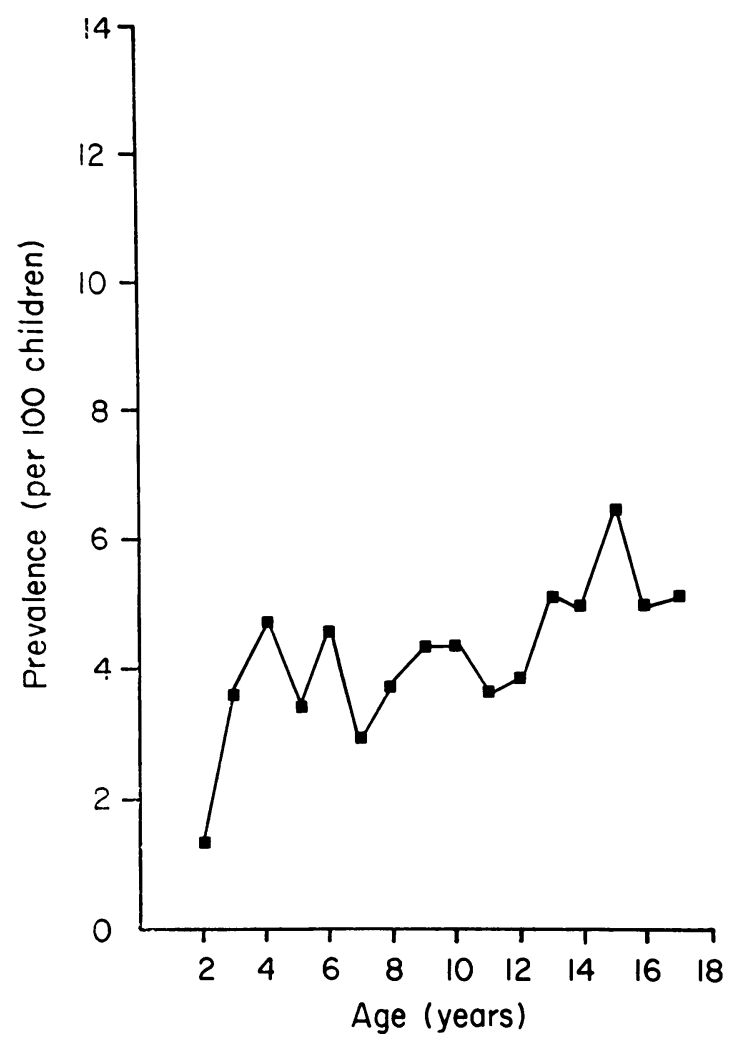

Fig. 5 Variation in prevalence of innocent pulmonary ejection systolic murmurs with age $(P<0.01)$.

\section{Discussion}

Physiological third heart sounds and innocent systolic murmurs are common auscultatory findings in schoolchildren. In this survey, the vibratory systolic murmur was the most frequent of the innocent systolic murmurs. It was prevalent throughout the 2- to 18-year age group and, in contrast to the findings of other workers, ${ }^{10} 1129$ there was no significant fall in prevalance among adolescents. The differentiation of vibratory and pulmonary ejection systolic murmurs is often illdefined $^{10} 111^{14}$ and, especially in an epidemiological study, is an academic exercise of little practical importance. In most instances, the innocent systolic murmur had the quality of both murmurs at different sites. Thus at the apex or lower left sternal border, there was the typical 'vibratory' intonation whereas at the second or third left inter- space it had more of the blowing character of a pulmonary ejection murmur. This led to confusion in the interpretation of these murmurs as shown by the pronounced variation in the observers' prevalence rates. Some observers considered such murmurs to be vibratory only, whereas the interpretation of others was that both a vibratory and a pulmonary ejection murmur were present in the same child. We are aware that the classical Still's murmur, which has typical uniform low frequency vibrations on a phonocardiogram (Fig. 2), has been shown by its response to a Valsalva manoeuvre ${ }^{9}$ and by other techniques ${ }^{30}$ to have a left-sided origin. Nevertheless, the use of the term 'innocent systolic murmur' to include both pulmonary ejection and vibratory systolic murmurs in children is now preferred. ${ }^{11}$

With a background of a high prevalence of rheumatic heart disease in this community, ${ }^{19}$ the recognition of the innocent nature of these murmurs is of special importance. Both overdiagnosis and underdiagnosis of rheumatic heart disease are harmful. Overdiagnosis may condemn some children to a prolonged antibiotic regimen, unnecessary limitation of activities, an overprotective parental attitude, difficulty in obtaining employment, and heavily loaded insurance policies. ${ }^{10}{ }^{31}$ On the other hand, underdiagnosis has the obvious danger of early rheumatic heart disease being missed and thus allowed to progress. Medical practitioners involved in the primary care of children in family practice or community health services should receive specialised training in the recognition of these murmurs. This survey suggested that even among observers training in auscultation, experience was of value in their detection. The features of most importance in differentiating innocent systolic murmurs from those caused by organic heart disease were their quality and characteristic behaviour with posture. The vibratory systolic murmur disappears or becomes softer on standing and this behaviour may partly explain why this murmur is less frequently heard in routine school examination programmes ${ }^{32}$ in which children are auscultated in the standing position only. A vibratory systolic murmur was present in only 15.9 per cent of Soweto children in the standing position. The intensity of the murmur was not meaningful since many murmurs $(63 \%)$ resulting from rheumatic mitral regurgitation were less than grade $3,{ }^{19}$ whereas some vibratory systolic murmurs were loud. The length and timing of the systolic murmur are also of limited value. Though a late or pansystolic murmur always indicates underlying organic heart disease, ${ }^{9}$ a murmur in midor early systole may be innocent or abnormal. ${ }^{5} 918$ The site of maximal intensity provides an important 
additional clue to the origin of the murmur particularly in small muscular ventricular septal defects, ${ }^{11}$ but site alone cannot always be used to differentiate innocent from pathological murmurs. Though any child suspected of having an abnormal systolic murmur was examined independently by three observers and a diagnosis of organic heart disease accepted only after agreement or discussion, ${ }^{20}{ }^{21}$ we cannot exclude the possibility that a few subjects whom we have classified as normal did, in fact, have minor cardiac pathology. It is difficult, for example, on clinical examination alone, and probably impossible during an epidemiological survey, to be certain of detecting all cases of small atrial septal defect, anomalous pulmonary venous drainage, or very mild mitral regurgitation reflected by an early, sometimes intermittent, apical murmur. ${ }^{5} 20$

A mid-diastolic murmur, which satisfied the criteria for being innocent, was a rare auscultatory finding. This entity has not received general recognition in textbooks on cardiology. Reference has been made to a ventricular filling murmur being mimicked by a left- and right-sided third sound occurring one after the other. ${ }^{14}{ }^{26}$ We support the observations of a few workers ${ }^{27} 28$ that short vibrations do occur in diastole in some apparently normal young individuals and may be heard as a murmur (Fig. 2). The origin of these vibrations is uncertain but they may be a result of rapid flow across the mitral or tricuspid valves. It has also been suggested ${ }^{28}$ that the vibrations arise during distension of the left ventricular wall, since they frequently start with a loud third heart sound. We have followed other children with this murmur and it has sometimes disappeared with time despite no rheumatic fever prophylaxis. In at least one child, however, a loud non-ejection systolic click later developed which suggested that there was, in fact, a minimal abnormality of the mitral valve. Since a short mid-diastolic murmur may be the only sign of minimal organic mitral stenosis, the diagnosis of an innocent mid-diastolic murmur should only be made after a careful but noninvasive cardiac assessment to exclude this more serious alternative. In addition, children with this murmur should be followed to observe its natural history.

We thank Drs K R Bloom, D M Bramwell-Jones, E Cohen, G E Gale, K Kanarek, and J B Lakier for their assistance in the auscultation of the children, and Professor D M Hawkins and Mr B Thomas (Department of Applied Mathematics, University of the Witwatersrand), and $\mathrm{Mr} R$ Garrison (Epidemiology Branch, National Heart,
Lung and Blood Institute, Bethesda, Maryland) for help with the statistical analyses.

\section{References}

'Still GF. Common disorders and diseases of childhood. 1st ed. London: H. Frowde, 1909.

${ }^{2}$ Mackenzie J. Diseases of the heart. London: Oxford University Press, 1925.

${ }^{3}$ Levine SA. The systolic murmur. Its clinical significance. $\mathcal{F} A M A$ 1933; 101: 436-8.

${ }^{4}$ Levine SA, Harvey WP. Clinical auscultation of the heart. Philadelphia, London: W. B. Saunders, 1949.

${ }^{5}$ Barlow JB, Pocock WA. The problem of non-ejection systolic clicks and associated mitral systolic murmurs: emphasis on the billowing mitral leaflet syndrome. Am Heart f 1975; 90: 636-55.

${ }^{6}$ Leatham A. A classification of systolic murmurs. $\mathrm{Br}$ Heart $\mathcal{F}$ 1955; 17 : 574.

${ }^{7}$ Leatham A. Auscultation of the heart. Lancet 1958; 2: 703-8.

${ }^{8}$ Fogel DH. The innocent systolic murmur in children: a clinical study of its incidence and characteristics. Am Heart f 1960; 59: 844-55.

${ }^{9}$ Barlow JB, Pocock WA. The isolated systolic murmur. $S$ Afr Med F 1965; 39: 909-18.

${ }^{10}$ Friedman S. Some thoughts about functional or innocent murmurs. Clin Pediatr (Phila) 1973; 12: 678-9.

${ }^{11}$ Tavel ME. The systolic murmur-innocent or guilty? Am f Cardiol 1977; 39: 757-9.

${ }^{12}$ Barlow JB, Pocock WA. The significance of aortic ejection systolic murmurs. Am Heart $\mathcal{f}$ 1962; 64: 149-58.

${ }^{13}$ Humphries JO, McKusick VA. The differentiation of organic and 'innocent' systolic murmurs. Prog Cardiovasc Dis 1962; 5: 152-71.

${ }^{14}$ Leatham A. Auscultation of the heart and phonocardiography. London: J. A. Churchill, 1970.

${ }^{15}$ Coleman EN, Doig WB. Diagnostic problems with innocent murmurs in children. Lancet 1970; 2: 228-32.

${ }^{16}$ Levy AM. Innocent murmurs. Cardiovasc Clin 1972; 4: No 3, 18-26.

${ }^{17} \mathrm{Br} \mathrm{Med} \mathcal{F}$ Editorial. Innocent praecordial murmurs in children. $1974 ; 1$ : 529-30.

${ }^{18}$ Lessof $M$, Brigden W. Systolic murmurs in healthy children and in children with rheumatic fever. Lancet 1957; 2: 673-4.

${ }^{10}$ McLaren MJ, Hawkins DM, Koornhof HJ, et al. Epidemiology of rheumatic heart disease in black schoolchildren of Soweto, Johannesburg. $\mathrm{Br} \mathrm{Med} \mathcal{F}$ 1975; 3: 474-8.

${ }^{20}$ McLaren MJ, Hawkins DM, Lachman AS, Lakier JB, Pocock WA, Barlow JB. Non ejection systolic clicks and mitral systolic murmurs in black schoolchildren of Soweto, Johannesburg. Br Heart f 1976; 38: 718-24.

${ }^{21}$ McLaren MJ, Lachman AS, Barlow JB. Prevalence of congenital heart disease in black schoolchildren of Soweto, Johannesburg. Br Heart $\mathcal{F}$ 1979; 41 : 554-8.

${ }^{22}$ Van der Hauwaert L, Nadas AS. Auscultatory findings in patients with a small ventricular septal defect. Circulation 1961 ; 23: 886-91. 
${ }^{23}$ Caceres CA, Perry LW. The innocent murmur. $A$ problem in clinical practice. Boston: Little, Brown, 1967. ${ }^{24}$ Rhodes PH. Diagnosis of innocent heart murmurs in children. Gen Pract 1955; 12: no. 1, 69-71.

${ }^{25}$ Harris TN. Phonocardiographic study of pulmonicsystolic murmurs in children. Am Heart $\mathcal{f} 1955$; 50: 805-15.

${ }^{26}$ Leatham A, Segal B, Shafter H. Auscultatory and phonocardiographic findings in healthy children with systolic murmurs. Br Heart $\mathcal{f} 1963$; 25: 451-9.

${ }^{27} \mathrm{Liebman}$ J, Sood S. Diastolic murmurs in apparently normal children. Circulation 1968; 38: 755-62.

${ }^{28}$ Luisada AA, Dayem MKA. Functional diastolic murmurs. Am Heart $\mathcal{f}$ 1972; 84: 265-72.

${ }^{29}$ de Monchy C, Van der Hoeven GMA, Beneken JEW. Studies on innocent praecordial murmurs in children. III. Follow up study of children with an innocent praecordial vibratory murmur. Br Heart $\mathcal{f} 1973 ; 35$ : 685-90.

${ }^{30}$ Wennevold A. The origin of the innocent 'vibratory' murmur studied with intra-cardiac phonocardiography. Acta Med Scand 1967; 181: 1-5.

${ }^{31}$ Bergman AB, Stamm SJ. The morbidity of cardiac nondisease in schoolchildren. $N$ Engl f Med 1967; 276: 1008-13.

${ }^{32}$ Stuckey D, Dowd B, Walsh H. Cardiac murmurs in schoolchildren. Med f Aust 1957; 1: 36-8.

Requests for reprints to Professor J B Barlow, Cardiac Unit, Department of Medicine, University of the Witwatersrand, Hospital Street, Johannesburg 2001, South Africa. 